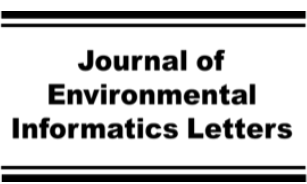

Www.iseis.org/jeil

\title{
Distribution Characteristics of Soil Moisture in the Three Rivers Headwaters Region, China
}

\author{
R. Cao ${ }^{1}$ and X. M. Jin ${ }^{2 *}$ \\ ${ }^{1}$ State Key Joint Laboratory of Environmental Simulation and Pollution Control, School of Environment, Beijing Normal University, \\ Beijing 100875, China. \\ ${ }^{2}$ School of Water Resources and Environment, China University of Geosciences, Beijing 100083, China.
}

Received 24 April 2021; revised 29 June 2021; accepted 30 July 2021; published online 16 August 2021

\begin{abstract}
The change of soil moisture has significant influence on the surface energy distribution and evapotranspiration process and causes the climatic environment changes. It is thus urgent to detect soil moisture facing climate change problems. Based on apparent thermal inertia method, the GLDAS soil moisture of the layer in $0 \sim 10 \mathrm{~cm}, 10 \sim 40 \mathrm{~cm}, 40 \sim 100 \mathrm{~cm}, 100 \sim 200 \mathrm{~cm}$ under the ground surface are proceeded for downscaling and the monthly soil moisture are obtained by combination of MODIS data. Statistics of precipitation and temperature of 13 meteorological stations in the Three River Headwater Region (TRHR) are collected to analyze the correlation between soil moisture change and temperature and precipitation. The correlation between soil moisture and evapotranspiration (ET) are analyzed by using the surface energy balance system model to calculate the average evapotranspiration in the study area. The result indicated that (1) Apparent thermal inertia (ATI) is positively correlated with soil depths in the four layers below the surface and has the best correlation with $0 \sim 10 \mathrm{~cm}$ soil moisture. Soil moisture increases with soil depth. Soil moisture is lowest under $0 \sim 10 \mathrm{~cm}$ depth while highest under $10 \sim 40 \mathrm{~cm}$ on average. (2) In terms of spatial distribution of TRHR, soil moisture is higher in the northwest and southeast, but lower in the southwest and northeast than average. The temporal variation of the soil moisture in one year was high in summer and low in winter, and the average annual soil moisture increased with time. (3) Soil moisture is negatively correlated with temperature and positively correlated with precipitation. There is a positive correlation between soil moisture and evapotranspiration. The linear regression coefficient of determination $R^{2}$ is 0.8489 .
\end{abstract}

Keywords: soil moisture, apparent thermal inertia (ATI), climatic factor, evapotranspiration (ET), Three River Headwaters Region (TRHR)

\section{Introduction}

Soil moisture is an important indicator of ecological environment monitoring in arid and semi-arid areas (Mohseni and Mokhtarzade, 2020). At the same time, it is the most sensitive limiting factor affecting vegetation growth (Seo et al., 2020). It has an important protective effect on the surface soil, and the water-deficient surface soil is susceptible to wind erosion ( $\mathrm{Ra}-$ khmatulina et al., 2021). Due to its far-reaching impact on flood forecasting, weather and climate forecasting, crop growth monitoring and water management applications, it is very important to obtain soil moisture information (Singh et al., 2021). Changes in soil moisture will cause changes in soil thermal properties, surface optical properties, and atmospheric moisture transmission, which will affect meteorological elements and are extremely sensitive to climate change (Kang et al., 2017). It is very important to accurately obtain the temporal and spatial distribution of soil moisture on a regional and global scale because it controls the exchange of energy, moisture and carbon

"Corresponding author. Tel.: +8613693096590; Fax: +86-10-82321081. E-mail address: jinxm@cugb.edu.cn (X. M. Jin).

ISSN: 2663-6859 print/2663-6867 online

(C) 2021 ISEIS All rights reserved. doi:10.3808/jeil.202100067. between the land surface and the atmosphere (Lei et al., 2014). A deep understanding of these processes has improved the research on simulating climate and terrestrial hydrology, which is helpful for hydrological simulation and the prediction of natural disasters ( $\mathrm{Li}$ et al., 2021). In the arid and semiarid regions of our country, evaporation from land surface accounts for a high proportion of precipitation (MacSween and Edwards, 2021). Precipitation is the main supplementary source of soil moisture, and evapotranspiration is closely related to soil moisture (Taktikou et al., 2016).

The Three River Headwaters Region (TRHR) is located in the hinterland of the Qinghai-Tibet Plateau and is the most important ecological protection area in China (Zheng et al., 2020). Its ecological environment has a huge ecological effect on the global natural environment, which has a wide-ranging impact on the survival and development of mankind ( $\mathrm{Li}$ et al., 2021). Sustainable ecological restoration and protection at different scales have been widely accepted and implemented as an important means to deal with environmental degradation (Bai et al., 2020). Soil moisture is the factor that has the greatest impact on the above-ground biomass of alpine grasslands in permafrost regions of the Qinghai-Tibet Plateau (Fan et al., 2019). Through remote sensing quantitative inversion methods, large-scale longsequence data can be obtained to facilitate macroscopic and dy- 
Table 1. Information of Weather Stations

\begin{tabular}{lllll}
\hline No. & Station & Latitude $\left(^{\circ}\right)$ & Longitude $\left(^{\circ}\right)$ & Hight $(\mathrm{m})$ \\
\hline 52908 & Wudaoliang & 35.22 & 93.08 & 4612.2 \\
52943 & Xinhai & 35.58 & 99.98 & 3323.2 \\
56004 & Tuotuo & 34.22 & 92.43 & 4533.1 \\
56018 & Zaduo & 32.88 & 95.28 & 4066.4 \\
56021 & Qumalai & 34.12 & 95.08 & 4175.0 \\
56029 & Yushu & 33.00 & 96.97 & 3716.9 \\
56033 & Maduo & 34.92 & 98.22 & 4272.3 \\
56034 & Qinshui & 33.08 & 97.13 & 4415.4 \\
56046 & Dari & 33.75 & 99.65 & 3967.5 \\
56065 & Henan & 34.73 & 101.60 & 13500.0 \\
56067 & Jiuzhi & 33.43 & 101.48 & 3628.5 \\
56125 & Nangqian & 32.20 & 96.47 & 3643.7 \\
\hline
\end{tabular}

namic monitoring of soil moisture changes (Dong et al., 2020). There will be great differences and uncertainties in the research results for different types of research areas, different methods and different time scales (Zhao et al., 2014). Wang et al. (2018) explored the influence of precipitation and temperature on soil moisture of different land cover types in the Tarim River Basin from 2001 to 2015. Partial correlation analysis and multiple linear regression analysis showed that precipitation in the study area had a positive feedback on soil moisture. The temperature has negative feedback, and the contribution of precipitation to the change of soil moisture is greater than that of temperature. Feng and Liu (2015) used cluster analysis to analyze the combined effects of precipitation and air temperature under different land covers in the Poyang Lake Basin in China from 2003 to 2009. Dari et al. (2021) assimilated multi-source remotesensed PSM into a high spatial resolution distributed hydrological model to improve the original remote-sensed soil moisture. The contribution of air temperature to soil moisture was greater than precipitation, and the impact of different surface temperatures on air temperature was even greater (Yao et al., 2019). During the growing season, they are significantly negatively correlated with atmospheric temperature. However, few research works focus on the combination of ATI method from MODIS products and GLDAS data to get the result of 4 layers soil moisture underground and analysis the impact factors of soil moisture such as precipitation, temperature and evapotranspiration in semi-arid areas (Martínez-Fernández et al., 2021).

In this study, the TRHR is selected as the research area. MODIS data is used to calculate the apparent thermal inertia (ATI) spatial distribution. And then the GLDAS data is used to obtain the soil moisture of underground $0 \sim 10 \mathrm{~cm}, 10 \sim 40 \mathrm{~cm}$, $40 \sim 100 \mathrm{~cm}$, and $100 \sim 200 \mathrm{~cm}$. Its distribution and influencing factors were analyzed and discussed. The results reveal the temporal and spatial distribution of soil moisture in the TRHR and the correlation between meteorology, precipitation and soil moisture, and the correlation and influence mechanism between soil moisture and evapotranspiration.

\section{Methodology}

\subsection{Data Collection}

In this study, the diurnal temperature and surface albedo products of moderate resolution MODIS spectral reflectance collected by aqua from January to December 2015 were used to retrieve regional soil moisture. It mainly includes land surface reflectance data set MYD09A1 (spatial resolution $500 \mathrm{~m}$ ) and land surface temperature data set MYD11A2 (spatial resolution $1000 \mathrm{~m}$ ), with time resolution of 8 days, 4 scenes per month, row number h25v05 and h26v05, totaling 576 scenes. The data is from the earth observation system data and information system (EOSDIS) of NASA website (http://reverb.echo.na sa.gov/reverb/). In order to keep the consistency of the research data, all the data were projected, converted, stitched and synthesized, and resampled to $500 \mathrm{~m}$ resolution.

GLDAS (the global land data assimilation system) is used to calculate soil moisture at different depths (four layers). The GLDAS data selected in this paper is GLDAS-2_0.25 with temporal resolution of 1 month and spatial resolution of $0.25^{\circ}$. Among the 36 bands of GLDAS data, four bands are selected to calculate soil moisture, which are $22 \sim 25$ layers of data, representing $0 \sim 10 \mathrm{~cm}, 10 \sim 40 \mathrm{~cm}, 40 \sim 100 \mathrm{~cm}$ and $100 \sim 200 \mathrm{~cm}$ soil moisture data under the surface, respectively, with the unit of $\mathrm{kg} \cdot \mathrm{m}^{-3}$.

The meteorological data needed for statistical analysis of the influence of meteorological factors on soil moisture comes from China Meteorological science data sharing service network (http://data.cma.cn). The monthly data set of climate (precipitation, temperature) data of China's international ground exchange station based on. In this study, a total of 13 meteorological stations in the study area were used to obtain the meteorological data of the study area by averaging the meteorological data provided by 13 meteorological stations.

\subsection{Apparent Thermal Inertia}

Apparent thermal inertia is a physical quantity that resists changes in the temperature of ground objects, reflects the energy exchange capacity between a substance and the surrounding environment, and can indicate changes in soil moisture. The advantages of this method are convenient calculation, low cost, and relatively high accuracy for low vegetation coverage areas, and high accuracy in the case of low vegetation coverage (NDVI $\leq 0.35$ ) (Van Doninck et al., 2011). Since the annual NDVI range of the study area is $0.25 \sim 0.30$, and the multi-year average value is 0.27 , the apparent thermal inertia method is suitable for the calculation of soil moisture in this area (Qin et al., 2013; Lei et al., 2014). 


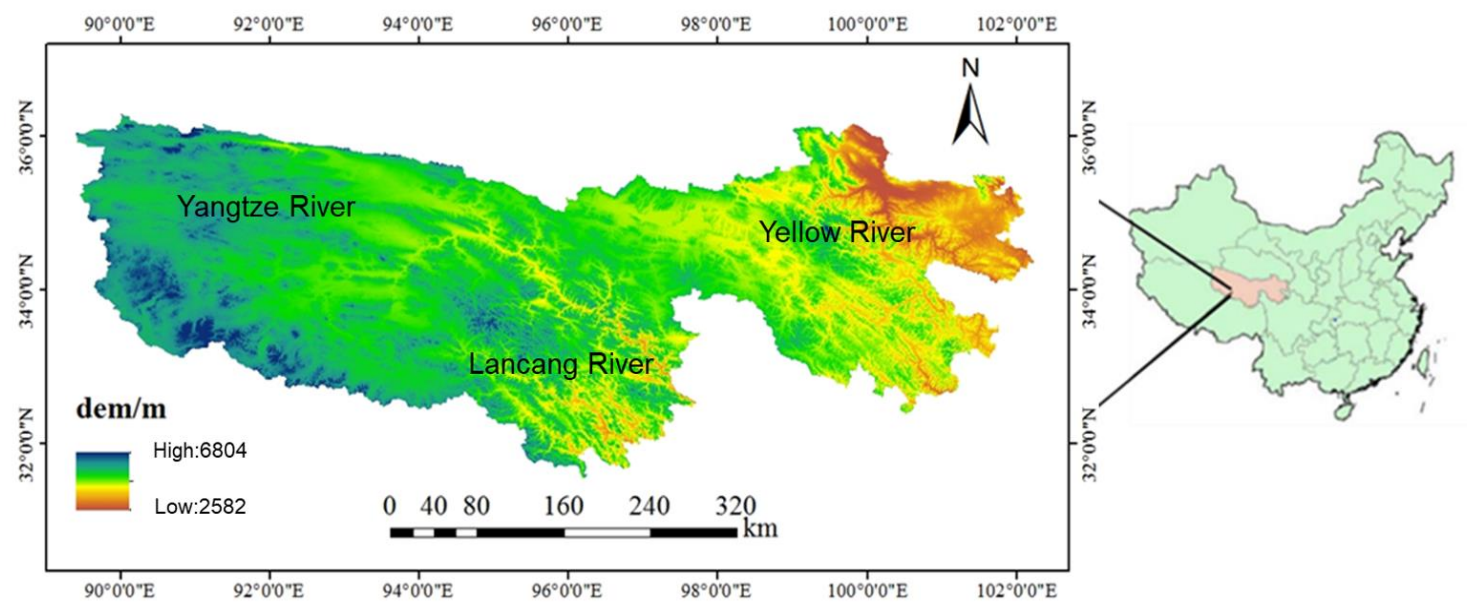

Figure 1. The geographical location of the source area of the TRHR.

The definition expression of apparent thermal inertia is:

$P=\sqrt{K \rho c}$

where $P$ is the apparent thermal inertia $\left(\mathrm{J} \cdot \mathrm{m}^{-2} \cdot \mathrm{K}^{-1} \cdot \mathrm{s}^{1 / 2}\right), K$ is the thermal conductivity $\left(\mathrm{J} \cdot \mathrm{m}^{-1} \cdot \mathrm{s}^{-1} \cdot \mathrm{K}^{-1}\right)$, and $\rho$ is the density $\left(\mathrm{kg} \cdot \mathrm{m}^{-3}\right)$, $c$ is the specific heat capacity of the soil at constant pressure $\left(\mathrm{J} \cdot \mathrm{kg}^{-1} \cdot \mathrm{K}^{-1}\right)$.

The calculation model of conventional apparent thermal inertia involves many physical parameters that are difficult to obtain, such as near-land surface temperature, surface temperature, surface roughness, air humidity, wind speed, etc. And the calculation is large and complicated (Verstraeten et al., 2006). Therefore, the simplification is based on the principle of energy balance, and only the surface temperature difference and surface reflectance are considered, and the influence of factors such as latitude and solar altitude is not calculated. The form of latent heat evapotranspiration is simplified. The simplified calculation formula is:

$A T I=\frac{1-A}{T_{d}-T_{n}}$

where $A T I$ represents the apparent thermal inertia, which is a dimensionless relative value, $A$ represents the full-band albedo of the surface, $T_{d}$ and $T_{n}$ represent the highest and lowest surface temperature in a day, respectively. The visible light, nearinfrared and thermal infrared can be passed through MODIS data.

The surface albedo $A$ refers to the ratio of the total reflected radiant flux on the surface to the incident radiant flux. The calculation of $A$ in this paper adopts the wide-band albedo instead of the full-band albedo algorithm. The calculation formula is as follows:

$$
\begin{aligned}
A= & 0.16 \alpha_{1}+0.291 \alpha_{2}+0.243 \alpha_{3}+0.116 \alpha_{4}+ \\
& 0.112 \alpha_{5}+0.081 \alpha_{7}-0.0015
\end{aligned}
$$

where $\alpha_{1}, \alpha_{2}, \alpha_{3}, \alpha_{4}, \alpha_{5}, \alpha_{7}$ are the surface reflectance in the bands $1,2,3,4,5$, and 7 respectively.

When using apparent thermal inertia to retrieve soil moisture, there is currently no unified theoretical model. This paper uses the simplest and most widely used linear empirical formula model for fitting, the formula is as follows:

$W=a+b \times A T I$

where $W$ is the soil moisture, and $a$ and $b$ are coefficients.

\section{Overview of Study Area}

The TRHR is located in the hinterland of the Qinghai-Tibet Plateau, under the jurisdiction of Yushu City, Golmud City, Tanggula Township, and 20 counties including Hainan Tibetan, Guoluo Tibetan, Huangnan Tibetan, and Yushu Tibetan, with a total area of $34.30 \times 10^{4} \mathrm{~km}^{2}$. It accounts for about $50.3 \%$ of the total area of Qinghai Province (Zhang et al., 2018). It is the most important ecological protection area in China and an important source of freshwater resources in China and Asia.

Affected by geological movement, the altitude of the study area varies greatly, and there are many mountains and mountains, relatively high altitude, low temperature, there are a large number of seasonal frozen soil and permafrost, which will have a certain impact on the temporal and spatial distribution of soil water and groundwater (Figure 1). The spatial distribution of soil has obvious vertical distribution from high to low in alpine desert, alpine meadow, gray cinnamon soil, chestnut soil and mountain forest soil (Jiang et al., 2017). This area not only has large surface runoff and abundant surface water resources, Moreover, the groundwater reserves are large enough, the buried depth is relatively shallow, the water quality is good, and the extraction rate is low. Groundwater is mainly distributed in hilly areas, and the distribution types are mainly bedrock structural fissure water and clastic rock weathered pore fissure water, with significant anisotropy. Groundwater replenishment methods are mainly vertical replenishment of precipitation and replen- 
ishment of melted ice and snow. The water cycle time period is updated quickly, so the salinity is low (Zheng et al., 2018).

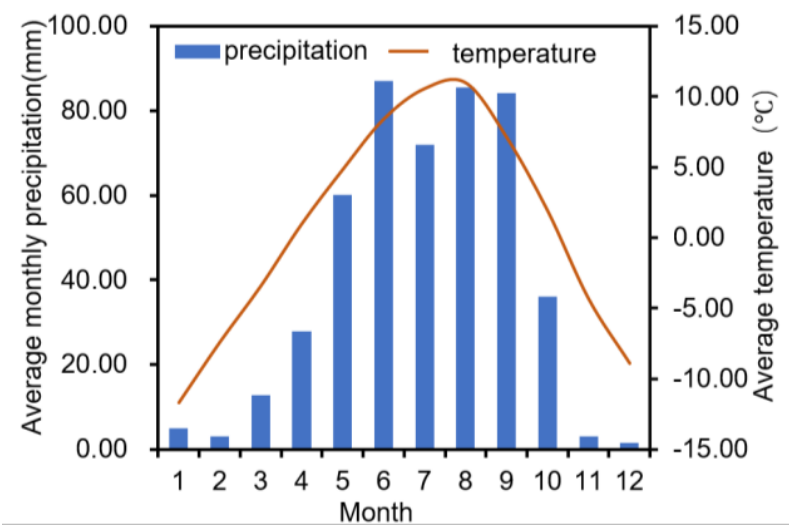

Figure 2. Average meteorological elements of TRHR in $2015 \sim 2017$.

Due to its special geographical location, abundant natural resources and strong ecological functions, the Three Rivers source has become an important nature reserve on the QinghaiTibet Plateau. However, due to the high altitude and harsh natural conditions in this area, its ecosystem is very fragile. Its ecological structure is simple, and its ability to resist disturbance and self-recovery is low. The ecological environment problems caused by it directly restrict the economic development of the downstream and affect the ecological environment of the downstream. Soil moisture is a key factor affecting the ecological process, ecological carrying capacity and restoration of degraded grasslands on the Qinghai-Tibet Plateau. The increase of soil moisture during the growing season of alpine grassland is beneficial to the growth of grassland vegetation (Liang et al., 2016).

The annual average temperature is $0.76^{\circ} \mathrm{C}$ in the study period as shown in Figure 2. The highest temperature was in $\mathrm{Au}-$ gust, with an average temperature of $10.99^{\circ} \mathrm{C}$; the lowest temperature is $-11.68^{\circ} \mathrm{C}$ in January. Generally speaking, the temperature is high in summer and low in winter. The annual average precipitation is $478.01 \mathrm{~mm}$, in which the precipitation from June to September accounts for the largest proportion, accounting for $68.74 \%$ of the annual average precipitation, while the precipitation from November to February is very small. The average annual evapotranspiration is $463.77 \mathrm{~mm}$. The annual sunshine hours are $2300 \sim 2900 \mathrm{~h}$, the sunshine percentage is $50 \sim$ $65 \%$, and the annual radiation is $5500 \sim 6800 \mathrm{~mJ} / \mathrm{m}^{2}$. Sandstorm days are generally about 19 days (Feng et al., 2018). The study area is particularly sensitive to climate change and may cause serious disturbance to the ecosystem.

\section{Results and Discussion}

\subsection{Distribution of ATI}

It can be seen from the inversion results of apparent thermal inertia that the apparent thermal inertia in Northeast and southwest is relatively low, especially in the Southwest (the source region of the Yangtze River). The low ATI value often occurs from January to April in winter, with the lowest ATI $<0.03$. However, ATI is relatively high in the southeast and northwest, especially in the southeast. High ATI values often occur from June to October in summer, with the highest ATI >0.05. The change trend with time mainly shows that the seasonal variation is significant, the average ATI value in summer is higher, and the average ATI value in winter is lower. The overall space is relatively unchanged.

The spatial distribution of annual ATI values is similar (Figure 3) and consistent with that of monthly ATI, with an increasing trend in time series, which is 0.0378 in 2015, 0.0387 in 2016 and 0.0404 in 2017. The dynamic change of time series (Figure 4) shows that the change in 2016 is relatively large, while the change in 2015 and 2017 is relatively small, and the curve is relatively flat. In 2016, there was an obvious drought in the first half of the year and a humid change in the second half of the year, with a large range of changes, which may be due to the government investment to take measures to protect and intervene, which has initially achieved certain results. By 2017, it still maintained a high ATI status, and the annual ATI value increased year by year. On the whole, ATI values change greatly within a year, with a maximum difference of 0.025 . The interannual variation is small and the trend is similar.

\subsection{Distribution of Soil Moisture}

The application scope of the apparent thermal inertia method is the low vegetation coverage area, while the TRHR is a semiarid area, the vegetation type is mainly grassland, the vegetation coverage is low, and thus the apparent thermal inertia method can be used to calculate the soil moisture. In ENVI, ATI data obtained by apparent thermal inertia method need to be converted to soil moisture data by downscaling equation. Correlation analysis was conducted between ATI and GLDAS soil water content data of $0 \sim 10 \mathrm{~cm}, 10 \sim 40 \mathrm{~cm}, 40 \sim 100 \mathrm{~cm}$ and $100 \sim 200 \mathrm{~cm}$ below the surface, and the downscaling equation was obtained (Figure 5). It can be seen from the figure that the four layers of soil moisture data at different depths have a good linear fitting with ATI, and the correlation coefficients are all above 0.5 , which can be used as a downscaling equation. Through the obtained ATI, the soil moisture at different depths can be calculated. The coefficient of determination $R^{2}=0.6008$ at $0 \sim 10 \mathrm{~cm}$ depth is the highest, the fitting is the best, and $R^{2}$ $=0.5071$ at $40 \sim 100 \mathrm{~cm}$ depth is the lowest.

From the spatial distribution map of soil moisture calculated by MODIS and GLDAS (Figure 6), it can be seen that the spatial distribution of soil moisture in the four layers is similar. Low in the northeast and southwest-mainly concentrated in the middle part of the source area of the Yangtze River where vegetation coverage is small and precipitation is small. The soil moisture in the first layer is mainly $23 \sim 25 \mathrm{~kg} / \mathrm{m}^{3}$, and the soil moisture in the second layer is mainly $72 \sim 75 \mathrm{~kg} / \mathrm{m}^{3}$, the soil moisture of the third layer is mainly $137 \sim 144 \mathrm{~kg} / \mathrm{m}^{3}$, and the soil moisture of the fourth layer is mainly $260 \sim 272 \mathrm{~kg} / \mathrm{m}^{3}$. High in the northwest and southeast-mainly concentrated in the source area of the Lancang River, the source area of the Yellow River, and other lower-elevation rivers, where there is a lot of water, vegetation coverage, and precipitation, and the northwest 


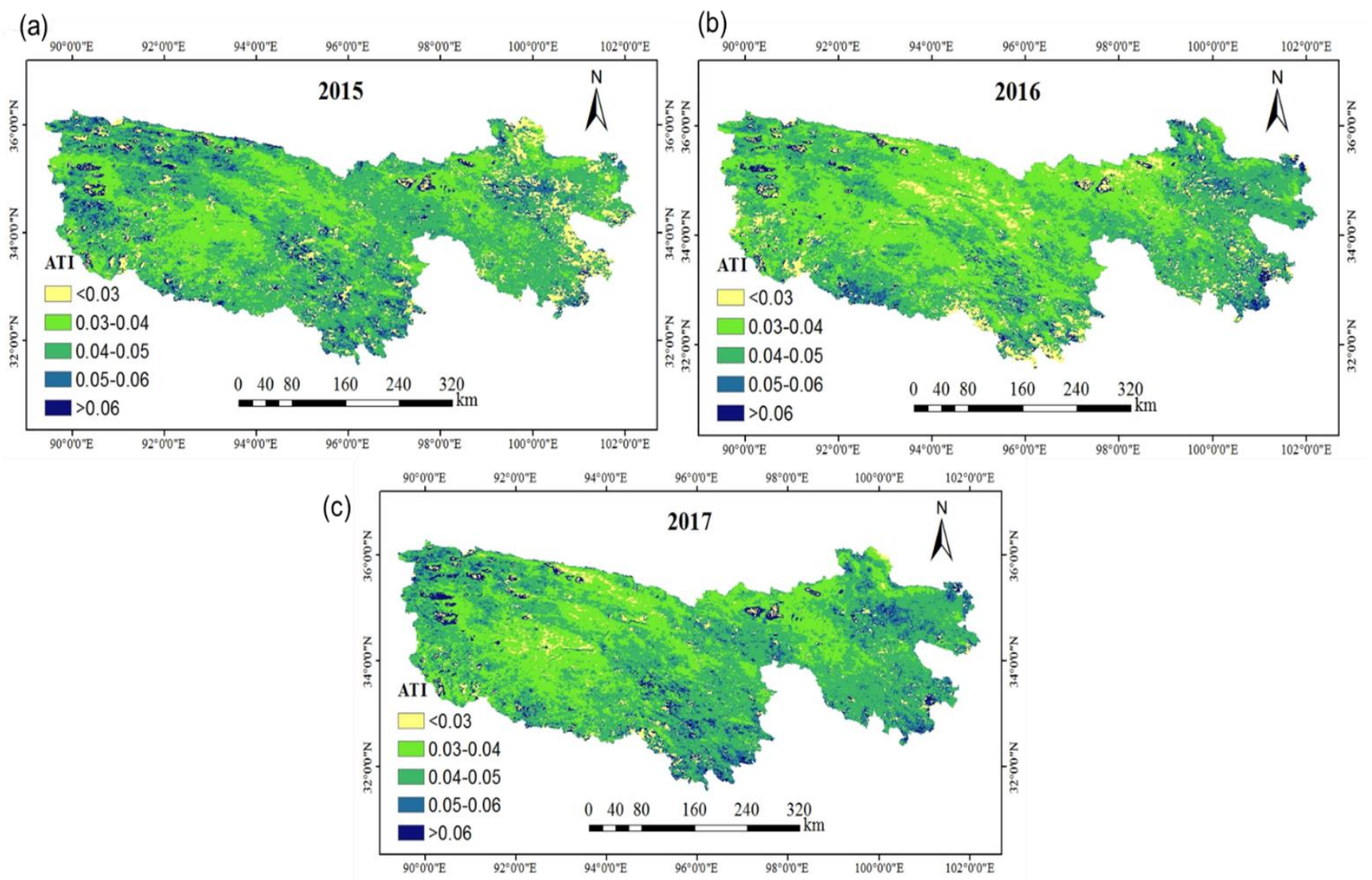

Figure 3. Spatial distribution of average annual ATI in the TRHR from 2015 to 2017.

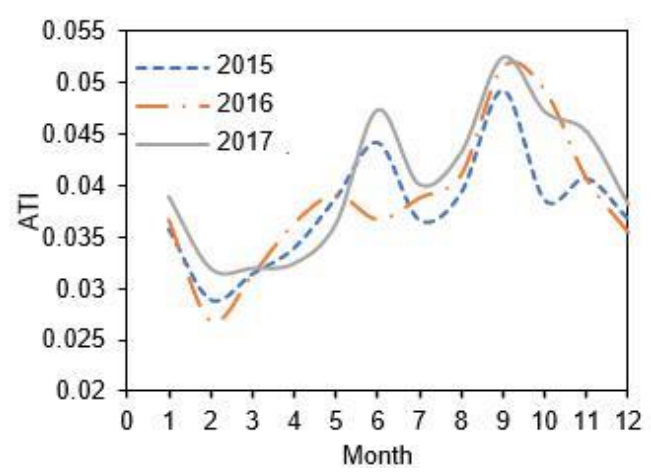

Figure 4. Dynamic changes of ATI time series from 2015 to 2017.

side of the Yangtze River source area and other higher-altitude mountains with more ice and snow melt In areas with low temperature, the soil moisture of the first layer is mainly $25 \sim 27$ $\mathrm{kg} / \mathrm{m}^{3}$, the soil moisture of the second layer is mainly $75 \sim 78$ $\mathrm{kg} / \mathrm{m}^{3}$, the soil moisture of the third layer is mainly $144 \sim 151$ $\mathrm{kg} / \mathrm{m}^{3}$, and the soil moisture of the fourth layer Mainly $272 \sim$ $284 \mathrm{~kg} / \mathrm{m}^{3}$. The spatial distribution of soil moisture has a good corresponding relationship with ATI. There are big differences in altitude, temperature, and precipitation between areas with high soil moisture and areas with low soil moisture on the cross section. As the soil depth deepens, the soil moisture increases significantly.

Soil moisture is an important indicator of the ecological environment, and its temporal change law has always been an important content of scientific research, which is related to the quality of vegetation growth and the degree of land desertification. According to the downscaling linear fitting method, the soil moisture results can be inverted. ArcGIS can be used to calculate the three-year average soil moisture of all pixels at different depths in the Three Rivers Source Region to statistically analyze the soil layers of different depths in the Three River Source Region from 2015 to 2017. The changes of monthly soil moisture during the year and between the years have a certain reference significance for the changes of the ecological environment in the plateau area.

As shown in Figure 7(a), on a time scale, the three-year average annual variation of soil moisture at different depths under the ground surface in the study area is high in summer and low in winter. The monthly average soil moisture is highest in September and lowest in February. The intra-year changes of the 4 layers are consistent, and the range of changes becomes more obvious as the depth increases. Fitting the average depth of each layer and the corresponding average soil moisture (Figure 7(b)) shows that the soil moisture in the TRHR increases linearly with the increase of depth. The soil moisture in the first layer is the low- 

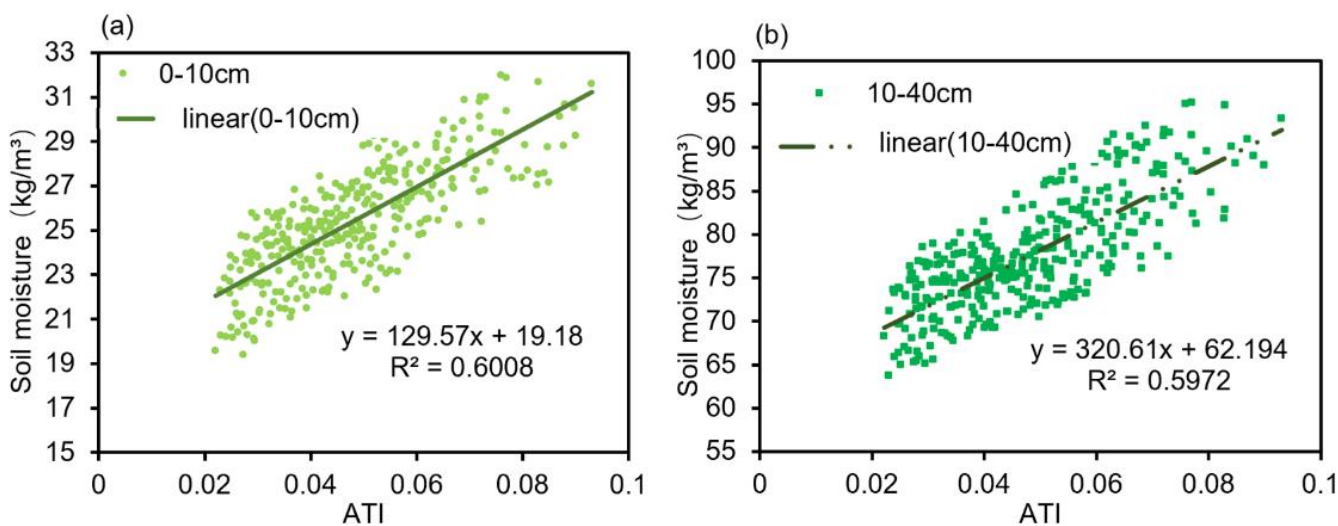

(c)
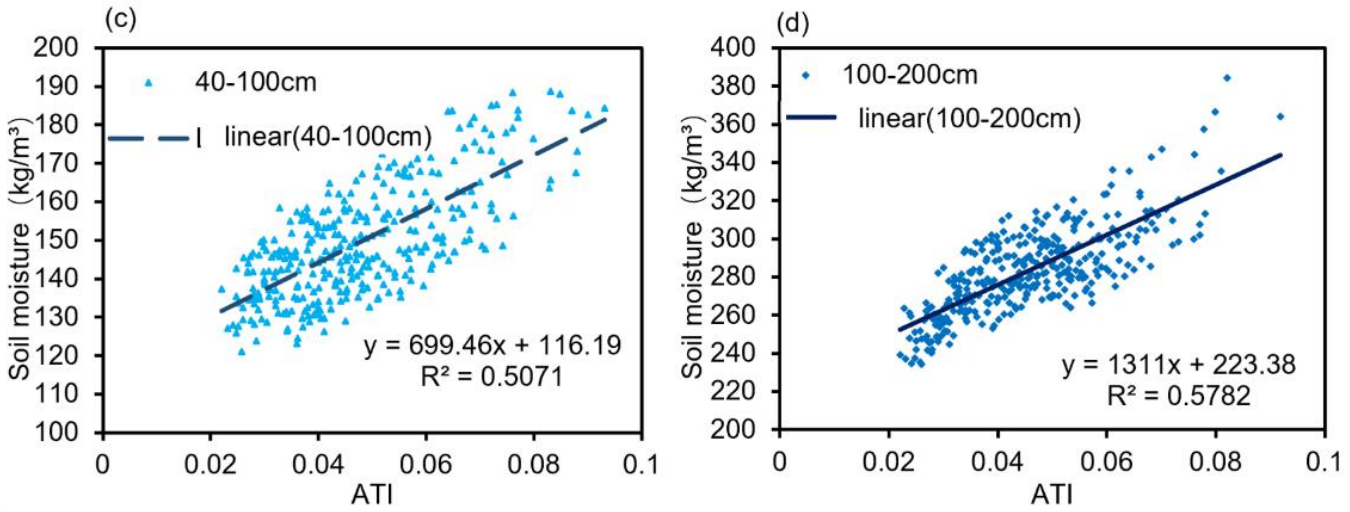

Figure 5. Correlation analysis of soil moisture data between ATI and GLDAS data.
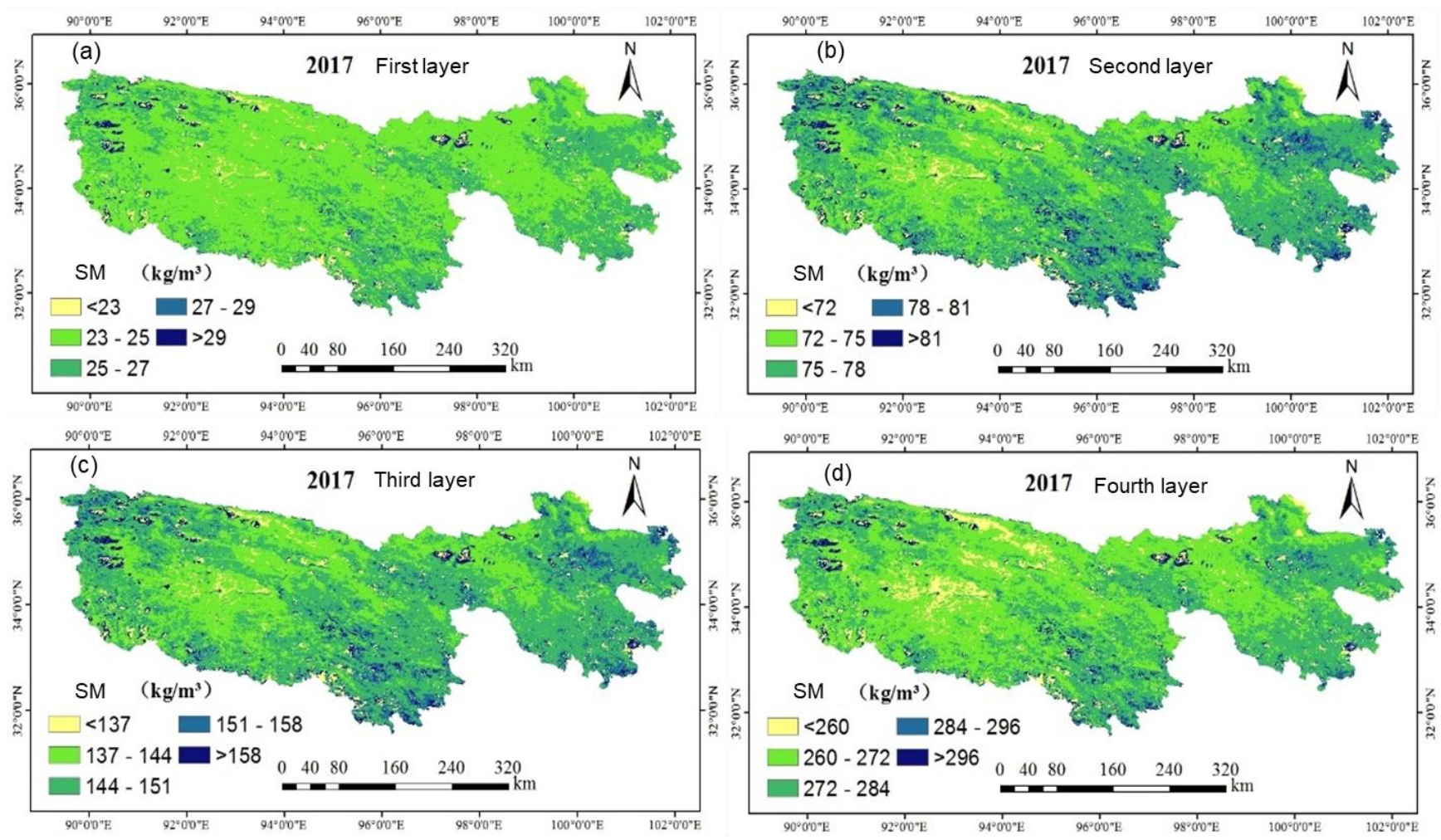

Figure 6. The spatial distribution of soil moisture at different depths in the TRHR in 2017. 
est, the soil moisture in the fourth layer is the highest, and the soil moisture in the fourth layer is the highest. The average soil moisture of the second layer is $67.56 \%$ higher than that of the first layer, the third layer is $47.87 \%$ higher than the second layer, and the fourth layer is $47.79 \%$ higher than the third layer.

The interannual variation of soil moisture in the four layers showed an increasing trend, and the trend became more obvious with the increase of soil depth (Figure 8). The change range in 2016 was more significant, with an obvious peak in September 2016 , and the soil moisture was $25.5685 \mathrm{~kg} / \mathrm{m}^{3}$, while the change range in 2015 and 2017 was smaller. The interannual variation of the same layer is small.
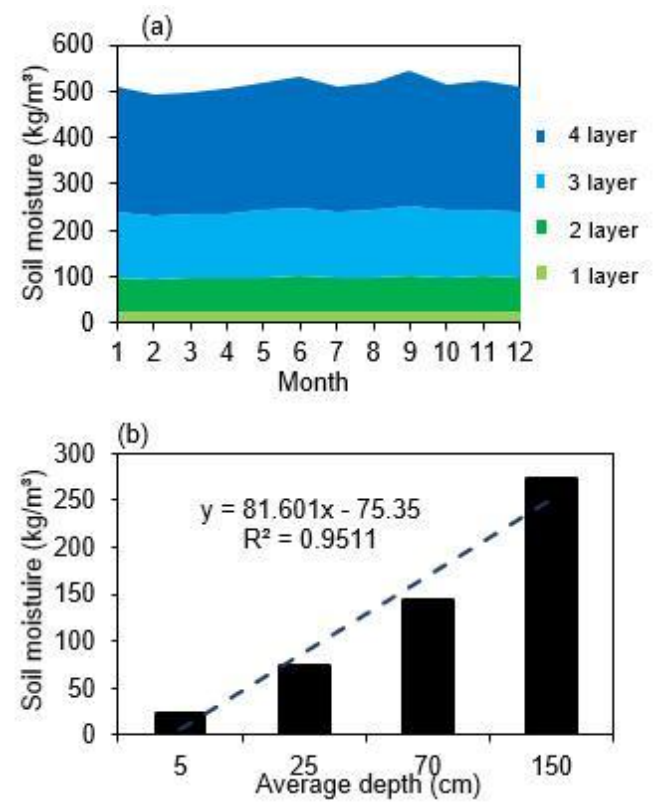

Figure 7. Annual average soil moisture change characteristics.

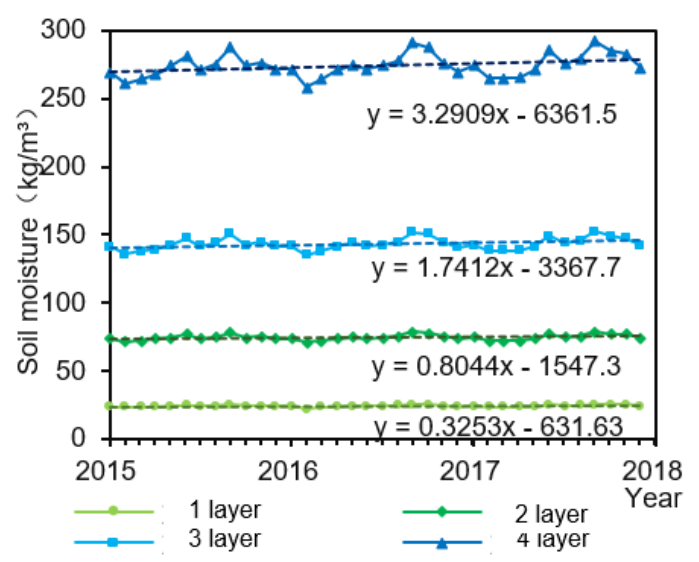

Figure 8. Time series variation characteristics of monthly soil moisture from 2015 to 2017.

\subsection{Analysis of Influencing Factors of Soil Moisture}

Meteorological factors are factors that have a great influ- ence on soil moisture. Analyzing the response characteristics of meteorological factors to soil moisture will help explain the relationship between regional soil moisture and climate factors. Precipitation and temperature are more related to soil moisture. This study separately counts the monthly average temperature and monthly total precipitation data of 13 meteorological stations in the study area from 2015 to 2017 for 12 months each year. The average value of the meteorological data of 13 meteorological stations is used to represent the overall precipitation and temperature data of the TRHR. Perform correlation analysis. Analyze the variation law of average soil moisture with precipitation and temperature for 36 months for 3 years, month by month, and analyze the influencing factors of soil moisture change. The changing trend of meteorological elements is shown in Figure 9. The temperature and precipitation values are large in summer months and small in winter months. The average temperature and precipitation in $2015 \sim 2017$ are generally increasing. For soil moisture, the closer it is to the surface, the greater the influence of climatic factors; the deeper the distance from the surface, the greater the influence of groundwater. Therefore, this article establishes the relationship between the first layer of soil moisture data and meteorological factors. Discuss the influence of climate factors on soil moisture.

The peak temperature occurs in the summer months, and August 2016 has the highest temperature in three years at $12.7^{\circ} \mathrm{C}$. Due to the limitations of the apparent thermal inertia method and the presence of a large amount of frozen soil in winter months, the calculation of soil moisture values in months with lower temperatures is not accurate enough, so we focus on the characteristic months of each year, namely June-September. Therefore, the temperature and soil moisture data from June to September $2015 \sim 2017$ are used for linear fitting. As can be seen from Figure $10 \mathrm{a}$, the slope is -0.2512 , which is negatively correlated, and the determination coefficient is higher, which is 0.6842 . The overall results show that temperature has a greater impact on surface soil moisture. The above research shows that there is a significant negative correlation between the soil moisture and temperature in the characteristic month of each year. The higher the temperature, the lower the soil moisture, and the lower the temperature, the higher the soil moisture. Precipitation is high in summer months and low in winter months, and the precipitation approaches zero. It is not difficult to find a positive correlation between soil moisture and precipitation in months with sufficient rainfall. However, the two are not synchronized in time. After rainfall infiltration and redistribution of soil water, the change in soil moisture slightly lags behind the change in precipitation. Taking three-year characteristic months (June to September) precipitation and soil moisture data to compare the correlation between the two by linear fitting (Figure 10(b)), it is found that the slope is greater than 0 , showing a positive correlation, and the coefficient of determination is 0.7351 , which is slightly higher than the temperature correlation with soil moisture, therefore, the influence of precipitation on soil moisture is also obvious.

Evapotranspiration includes soil surface evaporation, water surface evaporation, and plant transpiration. The monthly and annual evapotranspiration used in this paper refer to the 


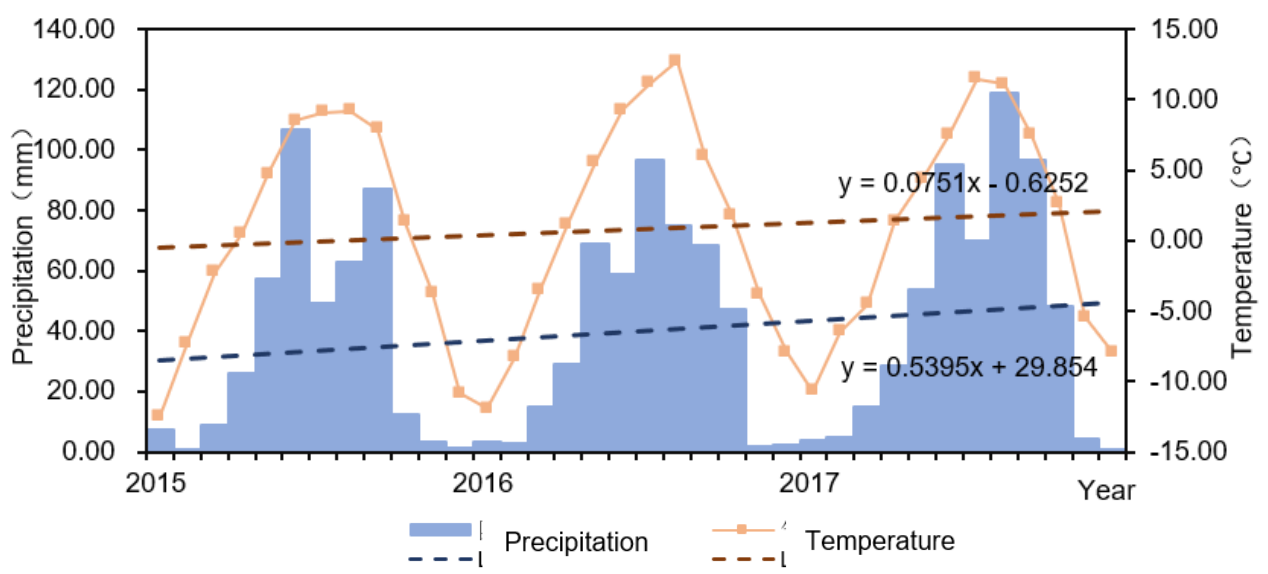

Figure 9. Monthly changes of meteorological elements in the TRHR from 2015 to 2017.
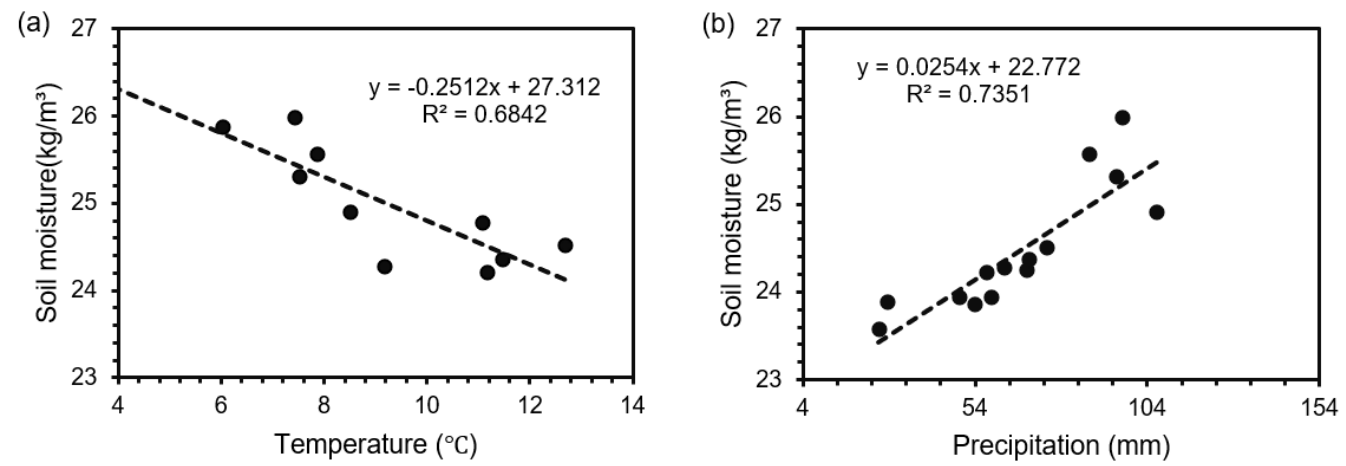

Figure 10. The influence of temperature and precipitation on soil moisture.

water consumption per unit area of soil surface, water surface, and plant leaf surface in a certain month and year, in $\mathrm{mm}$. There is a strong relationship between soil moisture and evapotranspiration in the mechanism of action. The surface energy balance system (SEBS) model is used to calculate the monthly average daily evapotranspiration for a total of 36 months in 12 months per year from 2015 to 2017 . From the comparison of the interannual soil moisture and evapotranspiration space from 2015 to 2017 in Figure 11, it can be seen that the spatial distribution of the two is very similar. The soil moisture and evapotranspiration in the northwest and southeast of the study area are relatively high. The soil moisture is concentrated in $25 \sim 27 \mathrm{~kg} / \mathrm{m}^{3}$, and the soil moisture and evapotranspiration in the northeast and southwest are relatively low, and the soil moisture is concentrated in $23 \sim 25 \mathrm{~kg} / \mathrm{m}^{3}$. In 2015, the spatial distribution of soil moisture and evapotranspiration both have greater spatial difference, while the spatial dispersion in 2016 and 2017 is small, the distribution of the mean value of soil moisture and evapotranspiration at each pixel point is more concentrated, and the spatial difference is small.

According to the calculation results of evapotranspiration, it is found that the regions with higher evapotranspiration and the regions with higher soil moisture are more consistent in spatial distribution. Therefore, the regional statistics module in ArcGIS counts the soil moisture for a total of 36 months from 2015 to 2017, and analyzes the month Average soil moisture and monthly evapotranspiration of the corresponding month, multiply the calculated daily evapotranspiration by the number of days in the month to obtain the monthly evapotranspiration and the monthly average soil moisture content retrieved from the corresponding month for correlation analysis, because the summer months have higher temperatures The apparent thermal inertia method is more suitable, so the correlation analysis is carried out with the soil moisture and monthly evapotranspiration of the characteristic month. The analysis result is shown in Figure 12. The determination coefficient of the two is as high as 0.8489 , which shows that soil moisture and evapotranspiration are significantly positively correlated with each other, which affects the surface water cycle in the study area.

\section{Conclusions}

Based on the collection of MODIS, DEM, GLDAS, meteorology and other data in the TRHR, this study uses quantitative remote sensing technology, based on the apparent thermal inertia method to retrieve the apparent thermal inertia of the TRHR, and calculates and analyzes the apparent heat Correlation between inertia and GLDAS soil moisture data at different depths of 4 layers underground, a correlation equation of two variables is established as a downscaling equation. The down- 

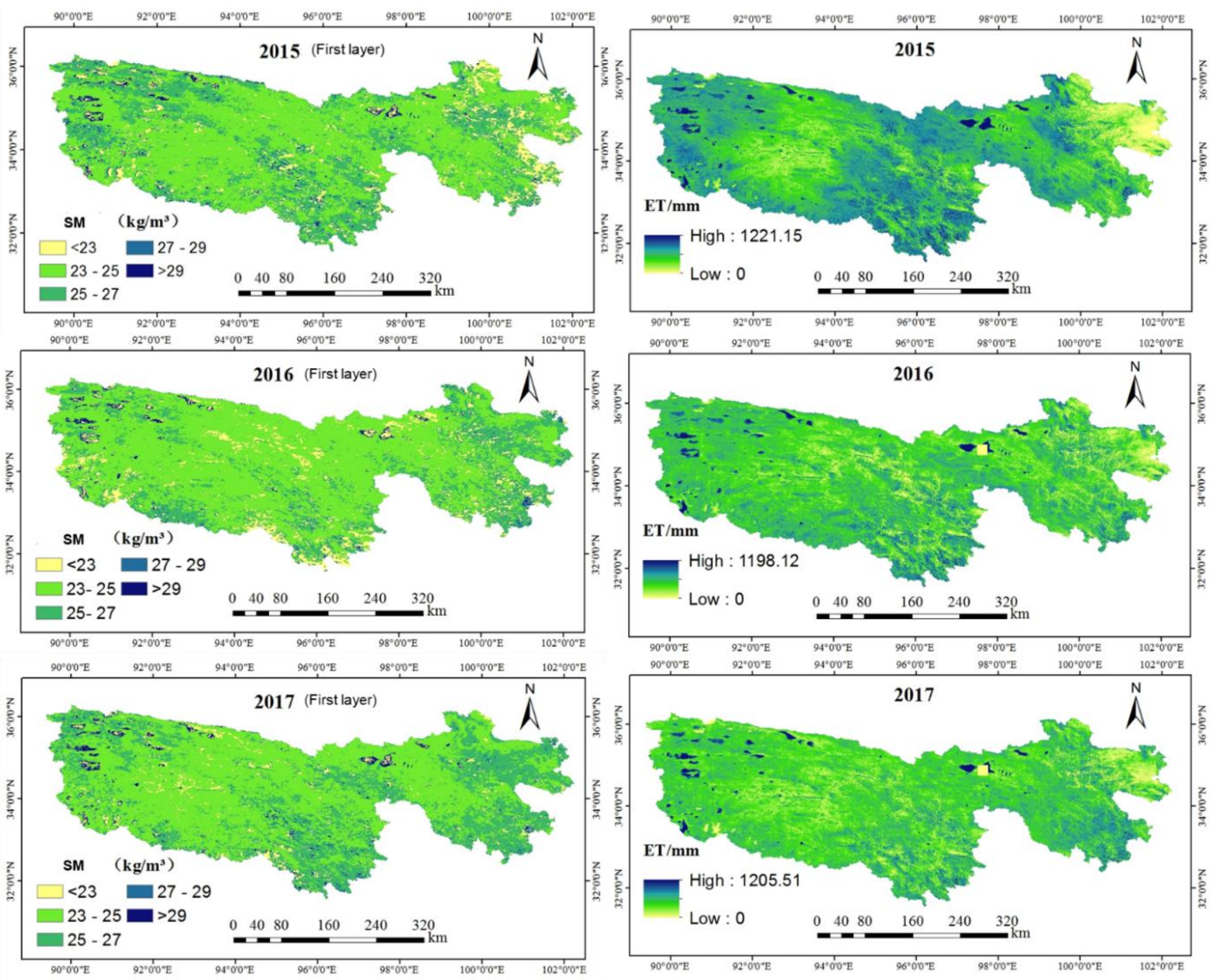

Figure 11. Spatial distribution of average soil moisture and evapotranspiration from 2015 to 2017.

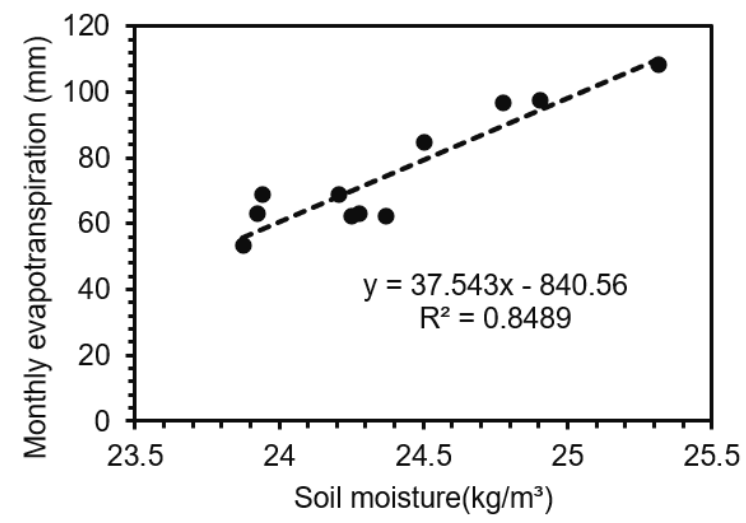

Figure 12. The effect of evapotranspiration on soil moisture.

scaling of GLDAS soil moisture data obtains the temporal and spatial distribution of soil moisture in the source area of the Three Rivers. Statistically analyze the multi-year variation pat-

terns of soil moisture and meteorological elements (mainly including precipitation and temperature) in the Three-River Source area, and analyze the impact of meteorological elements on the time series of soil moisture; estimate the evapotranspiration in the Three-River Source area based on the principle of surface energy balance, and make statistics and statistics. Quantitative analysis of evapotranspiration characteristics over the years and the correlation between soil water content and evapotranspiration. In summary, the following conclusions are obtained:

(1) The apparent thermal inertia (ATI) obtained by the inversion of the apparent thermal inertia method has a good correlation with the 4 layers of soil data below the surface of GLDAS, and the correlation with the $0 \sim 10 \mathrm{~cm}$ soil moisture data is the best. The inter-personal determination coefficient $R^{2}$ is 0.6008 , so the correlation equation between ATI and GLDAS soil moisture data can be used as a downscaling equation to downscale the GLDAS soil moisture data to obtain the soil moisture in the source area of the Three Rivers. 
(2) The soil moisture increases approximately linearly with the increase of depth. The first layer has the lowest soil moisture at $0 \sim 10 \mathrm{~cm}$, and the three-year average soil moisture is $24.2293 \mathrm{~kg} / \mathrm{m}^{3}$. The fourth layer has the highest soil moisture at $100 \sim 200 \mathrm{~cm}$, and the three-year average soil moisture. It is $274.4690 \mathrm{~kg} / \mathrm{m}^{3}$. The temporal and spatial changes of soil moisture in the four layers are consistent. As the depth increases, the change is more significant, and the soil moisture value fluctuates more. Spatially, soil moisture is high in the northwest and southeast, and low in the northeast and southwest. In terms of time, the changes in soil moisture during the year have obvious seasonal characteristics. The summer months are high and the winter months are low. The inter-annual soil moisture in $2015 \sim 2017$ showed a slow increase trend.

(3) Soil moisture has a strong correlation with meteorological factors and evapotranspiration. By establishing the correlation equation between soil moisture and air temperature and precipitation, it is concluded that soil moisture is negatively correlated with air temperature and positively correlated with precipitation, and the effect is obvious. The spatial distribution of soil moisture and evapotranspiration is highly consistent. The area with high soil moisture has high evapotranspiration, and the area with low soil moisture has low evapotranspiration. The time series are positively correlated and have obvious seasonality, which is characterized by high soil moisture and large evapotranspiration in summer months, and low soil moisture and low evapotranspiration in winter months.

In this study, the meteorological data is only a brief average processing, there is a certain degree of error, follow-up can be established by computer model, considering the terrain, the distribution of meteorological stations and other factors to get more accurate meteorological data. Moreover, the most concise linear correlation is used in the correlation analysis, but its reaction mechanism is very complex, and the follow-up work can try different correlation models to find the optimal solution. The causes of spatial distribution were not discussed in depth. In the follow-up study, the soil moisture can be calculated by terrain and vegetation coverage area, and the correlation analysis can be carried out to explore the possible influencing factors of spatial distribution of soil moisture in TRHR.

Acknowledgments. This research was supported by the National Key Research and Development Plan (2016YFA0601502) and the National Natural Science Foundation of China (41372250). The authors are grateful to the editors and the anonymous reviewers for their insightful comments and suggestions.

\section{References}

Bai, Y., Guo, C., Degen, A.A., Ahmad, A.A., Wang, W., Zhang, T., Li, W., Ma, L., Huang, M., Zeng, H., Qi, L., Long, R., and Shang, Z. (2020). Climate warming benefits alpine vegetation growth in Three-River Headwater Region, China. Science of the Total Environment, 742, 140574. https://doi.org/10.1016/j.scitotenv.2020.140 574

Dari, J., Quintana-Seguí, P., Escorihuela, M.J., Stefan, V., Brocca, L., and Morbidelli, R. (2021). Detecting and mapping irrigated areas in a Mediterranean environment by using remote sensing soil moisture and a land surface model. Journal of Hydrology, 596. https://doi. org/10.1016/j.jhydrol.2021.126129

Dong, J., Crow, W.T., Tobin, K.J., Cosh, M.H., Bosch, D.D., Starks, P.J., Seyfried, M., and Collins, C.H. (2020). Comparison of microwave remote sensing and land surface modeling for surface soil moisture climatology estimation. Remote Sensing of Environment, 242. https://doi.org/10.1016/j.rse.2020.111756

Fan, K., Zhang, Q., Singh, V.P., Sun, P., Song, C., Zhu, X., Yu, H., and Shen, Z. (2019). Spatiotemporal impact of soil moisture on air temperature across the Tibet Plateau. Science of the Total Environment, 649, 1338-1348. https://doi.org/10.1016/j.scitotenv.2018.08.399

Feng, H. and Liu, Y. (2015). Combined effects of precipitation and air temperature on soil moisture in different land covers in a humid basin. Journal of Hydrology, 531, 1129-1140. https://doi.org/10.1016/j.j hydrol.2015.11.016

Feng, S., Guo, L., Li, D., and Huang, Q. (2018). Spatial patterns of landscape change in the three rivers headwaters region of China, 19872015. Acta Ecologica Sinica, 38, 76-80. https://doi.org/10.1016/J.C HNAES.2017.05.004

Jiang, C., Zhang, L., and Tang, Z. (2017). Multi-temporal scale changes of streamflow and sediment discharge in the headwaters of Yellow River and Yangtze River on the Tibetan Plateau, China. Ecological Engineering, 102, 240-254. https://doi.org/10.1016/j.ecoleng.2 017.01.029

Kang, J., Jin, R., Li, X., Ma, C., Qin, J., and Zhang, Y. (2017). High spatio-temporal resolution mapping of soil moisture by integrating wireless sensor network observations and MODIS apparent thermal inertia in the Babao River Basin, China. Remote Sensing of Environment. 191, 232-245. https://doi.org/10.1016/j.rse.2017.01.027

Lei, S.G., Bian, Z.F., Daniels, J.L., and Liu, D.L. (2014). Improved spatial resolution in soil moisture retrieval at arid mining area using apparent thermal inertia. Transactions of Nonferrous Metals Society of China, 24, 1866-1873. https://doi.org/10.1016/S1003-6326(14)6 3265-9

Li, Z.L., Leng, P., Zhou, C., Chen, K.S., Zhou, F.C., and Shang, G.F. (2021). Soil moisture retrieval from remote sensing measurements: Current knowledge and directions for the future. Earth-Science Reviews, 218, 103673. https://doi.org/10.1016/j.earscirev.2021.103 673

Liang, T., Yang, S., Feng, Q., Liu, B., Zhang, R., Huang, X., and Xie, H. (2016). Multi-factor modeling of above-ground biomass in alpine grassland: A case study in the Three-River Headwaters Region, China. Remote Sensing of Environment, 186, 164-172. https://doi.org/10.1 016/j.rse.2016.08.014

MacSween, K. and Edwards, G.C. (2021). The role of precipitation and soil moisture in enhancing mercury air-surface exchange at a background site in south-eastern Australia. Atmospheric Environment, 255, 118445. https://doi.org/10.1016/j.atmosenv.2021.1184 45

Martínez-Fernández, J., González-Zamora, A., and Almendra-Martín, L. (2021). Soil moisture memory and soil properties: An analysis with the stored precipitation fraction. Journal of Hydrology, 593. https://doi.org/10.1016/j.jhydrol.2020.125622

Mohseni, F. and Mokhtarzade, M. (2020). A new soil moisture index driven from an adapted long-term temperature-vegetation scatter plot using MODIS data. Journal of Hydrology, 581, 124420. https:// doi. org/10.1016/j.jhydrol.2019.124420

Qin, J., Yang, K., Lu, N., Chen, Y., Zhao, L., and Han, M. (2013). Spatial upscaling of in-situ soil moisture measurements based on MODISderived apparent thermal inertia. Remote Sensing of Environment, 138, 1-9. https://doi.org/10.1016/j.rse.2013.07.003

Rakhmatulina, E., Stephens, S., and Thompson, S. (2021). Soil moisture influences on Sierra Nevada dead fuel moisture content and fire risks. Forest Ecology and Management, 496, 119379. https://doi. org/10.1016/j.foreco.2021.119379

Seo, M.G., Shin, H.S., and Tsourdos, A. (2020). Soil moisture retrieval from airborne multispectral and infrared images using convolutional 
neural network. IFAC-PapersOnLine, 53, 15852-15857. https://doi org/10.1016/j.ifacol.2020.12.240

Rawat, K.S., Sehgal, V.K., Singh S.K., and Ray, S.S. (2021). Soil moisture estimation using triangular method at higher resolution from MODIS products. Physics and Chemistry of the Earth, 103051. https://doi.org/10.1016/j.pce.2021.103051

Taktikou, E., Bourazanis, G., Papaioannou, G., and Kerkides, P. (2016). Prediction of soil moisture from remote sensing data. Procedia Engineering, 162, 309-316. https://doi.org/10.1016/j.proeng.2016.11. 066

Van Doninck, J., Peters, J., De Baets, B., De Clercq, E.M., Ducheyne, E., and Verhoest, N.E.C. (2011). The potential of multitemporal Aqua and Terra MODIS apparent thermal inertia as a soil moisture indicator. International Journal of Applied Earth Observation and Geoinformation, 13, 934-941. https://doi.org/10.1016/j.jag.2011.07.003

Verstraeten, W.W., Veroustraete, F., Sande, C.J., Grootaers, I., and Feyen, J. (2006). Soil moisture retrieval using thermal inertia, determined with visible and thermal spaceborne data, validated for European forests. Remote Sensing of Environment, 101, 299-314. https:// doi.org/10.1016/j.rse.2005.12.016

Wang, Y., Yang, J., Chen, Y., Wang, A., and De Maeyer, P. (2018). The spatiotemporal response of soil moisture to precipitation and temperature changes in an arid region, China. Remote Sensing, 10. https://doi.org/10.3390/rs10030468

Yao, Y., Zhang, Y., Liu, Q., Liu, S., Jia, K., Zhang, X., Xu, Z., Xu, T., Chen, J., and Fisher, J.B. (2019). Evaluation of a satellite-derived model parameterized by three soil moisture constraints to estimate terrestrial latent heat flux in the Heihe River basin of Northwest Chi- na. Science of the Total Environment, 695, 133787. https://doi.org/ 10.1016/j.scitotenv.2019.133787

Zhang, T., Li, B., Yuan, Y., Gao, X., Sun, Q., Xu, L., and Jiang, Y. (2018). Spatial downscaling of TRMM precipitation data considering the impacts of macro-geographical factors and local elevation in the ThreeRiver Headwaters Region. Remote Sensing of Environment, 215, 109127. https://doi.org/10.1016/j.rse.2018.06.004

Zhao, L., Yang, K., Qin, J., Chen, Y., Tang, W., Lu, H., and Yang, Z.L. (2014). The scale-dependence of SMOS soil moisture accuracy and its improvement through land data assimilation in the central Tibetan Plateau. Remote Sensing of Environment, 152, 345-355. https:// doi.org/10.1016/j.rse.2014.07.005

Zheng, D., Wang, Y., Hao, S., Xu, W., Lv, L., and Yu, S. (2020). Spatialtemporal variation and tradeoffs/synergies analysis on multiple ecosystem services: A case study in the Three-River Head-waters region of China. Ecological Indicators, 116, 106494. https://doi.org/10.10 16/j.ecolind.2020.106494

Zheng, Y., Han, J., Huang, Y., Fassnacht, S.R., Xie, S., Lv, E., and Chen, M. (2018). Vegetation response to climate conditions based on NDVI simulations using stepwise cluster analysis for the Three-River Headwaters region of China. Ecological Indicators, 92, 18-29. https://doi. org/10.1016/j.ecolind.2017.06.040

Li, Z.J., Li, Z.X., Feng, Q., Wang, X.F., Mu, Y.H., Xin, H.J., Song, L. L., Gui, J., Zhang, B.J., Gao, W.D., Xue, J., Li, Y.C. Yang, A., Nan, F.S., Liang, P.F., and Duan, R. (2021). Hydrological effects of multiphase water transformation in Three-River Headwaters Region, China. Journal of Hydrology, 601, 126662. https://doi.org/10.1016/j.jhyd rol.2021.126662 